Vol. 2, No. 1, 2017

\title{
DIGITAL INTERFACES IN CYBER-PHYSICAL SYSTEMS
}

\author{
Andrii Grebeniak, Eugene Miyushkovych, Yaroslav Paramud \\ Lviv Polytechnic National University, 12, S. Bandera str., Lviv, 79013, Ukraine \\ Author e-mail: breskyl@gmail.com
}

Submitted on 08.05.2017

(C) Grebeniak A., Miyushkovych E., Paramud Y., 2017

\begin{abstract}
The analysis of structural solutions of autonomous measuring-computing nodes (AMCN) Ethernet - oriented cyber-physical systems (CPS) have been conducted. The possibility of using the standard industrial sensors and actuators with low-speed serial ports in them have been showned. General basis of telecommunication subsystems has been given. The basic options of realization of telecommunications subsystems have been proposed and the recommendations about choosing a concrete decision by the criterion of necessary computing power for primary data processing. The physical model of telecommunication subsystems has been investigated.
\end{abstract}

Index Terms: cyber-physical system, telecommunication subsystem, autonomous measuring-computing node, serial port.

\section{INTRODUCTION}

The fast development of computer technologies promotes widening spheres of their applications. Cyberphysical systems are one of the variants of such application. The problem of creating effective cyberphysical systems is actual and studies in this area are advisable.

Analysis of actual researches and publications. The versatility of cyber-physical systems creates the preconditions for a broad range of research on approaches and principles of their construction. Among the latest are the studies of cyber-physical systems, whose results are published in the conceptual scientific works [1-4].

In the works it has been installed that in a separate cyber-physical systems important components are autonomous measuring and computing nodes (AMCN) responsible for primary data processing, and telecommunications facilities, whose main aim is to ensure effective exchange of information. In work [5] the concept of the use of telecommunications interfaces in the CFS has been investigated. In work [6] classification and application features of telecommunication interfaces have been proposed, the feasibility of building telecommunication components of scalable cyber-physical systems based on industrial Ethernet and / or Wi-Fi have been proved.

It should be noted that these interfaces are not the most common among the typical industrial measuring and control instruments that will be connected to an autonomous measuring and computing node. Accordingly, in the telecommunications subsystems
(COMMS) there is a need to use interface bridges and other rational structural, algorithmic, circuitry, software solutions. Therefore, the study of structural solutions of COMMS in the CPS is an urgent scientific and applied problem.

Formulation of the problem. When building hierarchical Ethernet-oriented CPS with serial industrial measuring and control means, it becomes necessary to use telecommunication subsystems for the purpose of integrating sensors and actuators that are equipped with serial ports (UART, RS-232, RS-485, Current Loop and etc.).

In the context of this article, the features of constructing rational structures of telecommunication subsystems are considered, taking into account the possibility of remote modification of algorithms and software for primary data processing.

\section{BASIC MATERIAL OF RESEARCH}

A generalized block scheme of an autonomous measuring-computing node of an Ethernet-oriented CPS is shown in Fig. 1. The main components are the telecommunications subsystem, sensors, actuators. COMMS consists of four main parts - a channel switching unit, a data processing and control unit, a remote software update unit and a network interface unit.

The channel switching unit, in addition to its main function, coordinates the signals of AMCN and industrial equipment at the physical level. The market has a wide range of transceivers for typical asynchronous serial interfaces of industrial networks, which allows you to choose the necessary solution for both technical (speed, transmission distance, power consumption) and economic parameters.

Interaction with industrial measuring and control means is generally bi-directional, therefore it is not advisable to separate dedicated channels for sensors and actuators. In the case of single-channel AMCN this block can be reduced to one transceiver.

The data processing and control unit select the channel for interaction, the primary processing of data from the sensors and the generation of control signals for the actuators. The required performance of the computing facilities of this unit is determined by the complexity of the data processing algorithms, the number of channels and the real information exchange rate. 


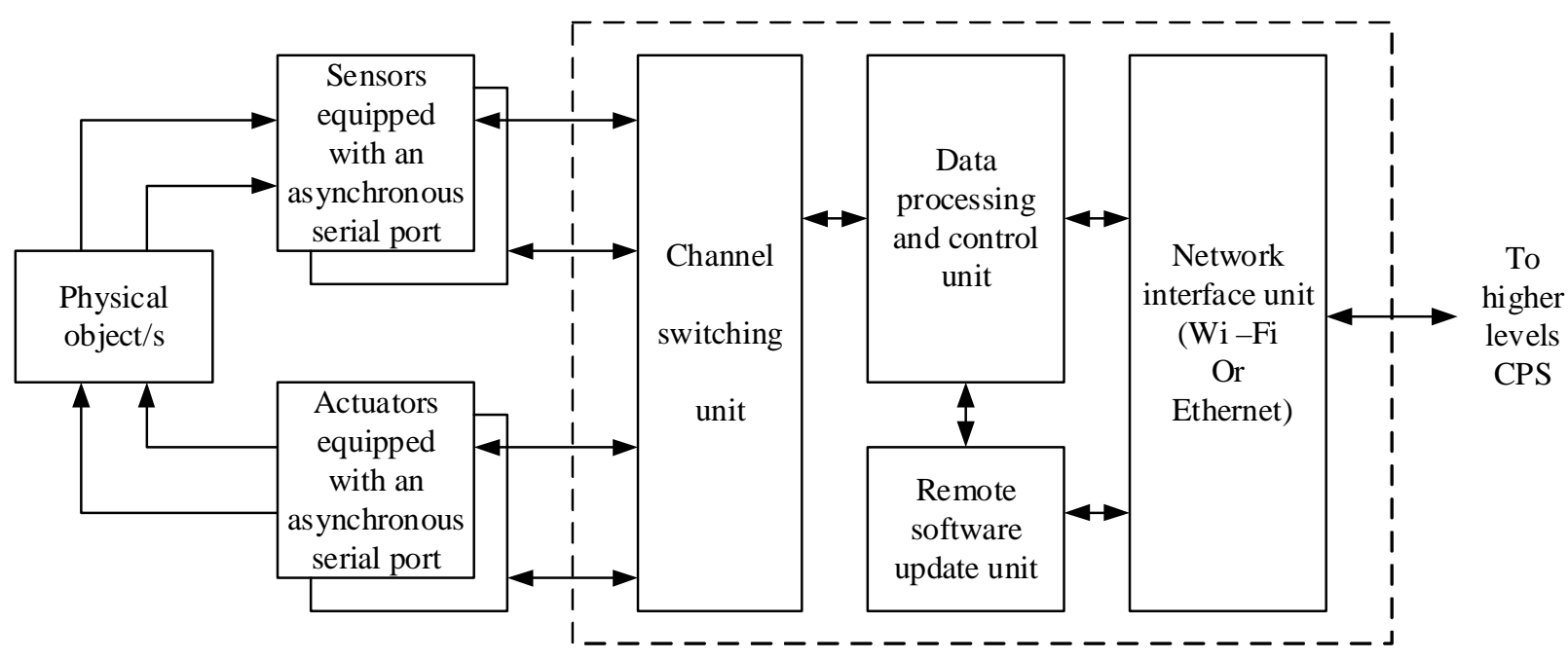

Fig. 1. Structural scheme of the autonomous measuring-computing node CPS

The remote software update unit allows you to replace the firmware of the data processing and management unit. Depending on the abilities of the AMCN hardware platform, it can be implemented either programmatically, that is, as a separate software module within the control unit, or as a hardware device in the form of a separate microcontroller.

The network interface unit can be implemented in several ways, the advantages and disadvantages of which will be discussed below.

\section{THE COMMUNICATION SUBSYSTEM (COMMS)}

Logical operating modes of the telecommunications subsystem of Ethernet-based CPS are based on the TCP / IP protocol stack. Its full-fledged implementation requires the use of fairly large computational resources, so the choice of means for implementing the network interface block is primarily determined by the availability of free computing resources in the core of the COMMS, that is, in the data processing and management unit.

In case that the tenseness of the information exchanges between AMCN and the upper levels of the CPS is low, it is advisable to implement the block of network interfaces in the form of an interface bridge.

It is expediently to implement the interface bridge as a specialized "system-on-chip" (SoC), the processing power of which is sufficient for the functioning of a Unix-like OS with closed code, which provides a full implementation of the TCP / IP stack.

Local updating of the embedded software is carried throughout the serial port of in-circuit programming of the ISSP main controller (In-System Serial Programming). Depending on the type of main controller, this can be a JTAG, I2C, SPI, UART or other interface.

Advantages of this approach are as follows:

- using the interface bridge as a complete solution (with the implementation of the TCP / IP stack by OS means) significantly reduces the development and debugging of the communication subsystem;

- the possibility of choosing a microcontroller depending on the complexity of the data processing algorithms (from 8-bit MCs to high-performance DSPs) in some cases (one channel, data processing is not required), you can abandon the microcontroller altogether, leaving only a transceiver and an interface bridge in the composition of COMMS;

- Disadvantages of this approach are as follows:

- the closed code of the built-in software interface bridge - the elimination of identified errors only in the new official firmware versions;

- the use of alternative firmware (eg. OpenWRT) deprives the interface bridge guarantee of manufacturer.

- Examples are the following: the bridge interface UART - Wi-Fi from Mediatek (MT7681), Marvell (88W8801), Wiznet (WizFi210), Espressif (ESP8266); module UART - Ethernet / Wi-Fi HLK-RM04 and many others. In this case, solutions are used only with original (official) versions of firmware.

To enable remote updating of the firmware of the data processing and control unit, a separate node - the programmer - is added to the structure of the basic structure of the COMMS.

In this situation, it will be expedient to use the interface bridge HLK-RM04, in which two UART interfaces are realized. The firmware of the programmer should be subjected to thorough testing, since its failure to change the main firmware will lead to the loss of AMCN operation as a whole.

The advantage of this solution is the ability to fully implement the programming protocol on a separate microcontroller, as well as the ability to re-program the main controller in case of failure during the previous attempt.

When the interface bridge allows the implementation of additional software user functionality on its own resources (for example, ESP8266 with alternative firmware), it becomes possible to implement a remote 
modification of the main embedded software without additional hardware costs as a separate microcontrollerprogrammer. For this purpose, on its unused generalpurpose terminals (GPIO), the corresponding interface of in-circuit programming (ISSP) is emulated programmatically.

In case of that the AMCN core has sufficient processing power, it is possible to implement the TCP / IP protocol stack programmatically in the data processing and control unit. In this event the functions of the network interface block are reduced to providing interaction at the physical and channel levels. It is possible to use both specialized interface chips that provide the implementation of physical and channel levels of Ethernet / Wi-Fi and microcontrollers with an integrated Ethernet physical layer interface.

An example of the latter may be the PIC18F67J60 manufactured by Microchip. It should be noted that microcontrollers with an integrated physical Ethernet level are relatively rare.

The protocol stack is usually provided as a proprietary library from the MK manufacturer. In its essence, this option is an implementation of the interface bridge in the form of an open hardware-software platform, all available resources of which are available to the developer. The functionals of the data processing unit and the control unit and the network interface unit are implemented on a common computing core, presenting increased requirements for the development of firmware.

The structural solution reviewed has the following advantages:

- minimization of hardware costs;

- with sufficient MK performance, it is possible to achieve a much higher intensity of information exchange with higher CPS levels as compared to options based on a closed interface bridge.

Disadvantages of this approach are as follows:

- increased complexity of creating embedded software;

- the proprietary TCP / IP stack with closed source code is usually paid;

- often, to save computing resources, only part of the TCP / IP stack is implemented;

- any changes in the algorithm of the functioning of the software require a flashing of the MK, that is not always possible to implement in a remote version, since the kernel at the time of changing the firmware must communicate with the source firmware.

The last shortage can be eliminated by introducing a separate hardware programming module into the COMMS with the following algorithm of work: first, the binary version of the updated firmware is loaded into the local memory of the programming module, and, subsequently, it initiates a master flashing session. The disadvantage of this scheme of remote modification of the firmware is the loss of the functionality of the AMCN in the event of a failure in the reprogramming process, since it is impossible to establish a connection for the firmware to be reloaded by the programmer.
In cases where complex data processing is required, there is a high intensity of information exchange with higher levels of CPS, frequent changes in processing algorithms are possible or full implementation of the TCP / IP stack is necessary, it is advisable to go to highlevel solutions, that is, to use single-board microcomputers.

A sufficiently high-performance single-board microcomputer with a full-fledged OS via the USB interface can be supplemented with appropriate network adapters. Typical representatives of this approach are single-board microcomputers of the Raspberry Pi series (models A, A, B, B +, 2B, Zero).

It is also possible to use a single-board microcomputer with an integrated Ethernet or Wi-Fi interface. A typical representative of this approach is the Raspberry Pi 3 single-board microcomputer.

These approaches have the following advantages:

- the possibility of installing an open source OS;

- flexibility in choosing the types and number of interfaces;

- change of algorithms of data processing by means of OS.

- The disadvantages include the following:

- increased power consumption;

- additional costs of CPU resources for OS support in general and, in particular, quite complicated in the implementation of the USB interface.

The use of a standard industrial PC (PC-104, PCI-104, etc.) with the corresponding boards of interface extensions can be considered as a special case of this approach. The peculiarity of this option is the possibility of implementing COMMS in industrial execution, but the price of such solution will be significantly higher than in previous cases.

\section{EXPERIMENTAL CHECKING.}

In order to test the possibility of practical implementation of the variants discussed above, several experimental physical models were collected, in particular COMMS with local updating of firmware on the basis of a programmable interface bridge. Block diagram of the physical model COMMS shown in Fig. 2.

For the organization of the network, a Wi-Fi module was selected based on the ESP8266 microcontroller from Espressif Systems. The model range of the module manufacturer is quite wide. The functionality of all varieties of the ESP8266 Wi-Fi module is similar and differs only in the number of additional I / O lines that are available to the user. These modules support Wi-Fi IEEE $802.11 \mathrm{~b} / \mathrm{g} / \mathrm{n}$ standards. The manufacturer is positioning these modules to work with an unauthorized microcontroller. The communication between the ESP8266 module and the external microcontroller is implemented via the UART interface using AT commands. 


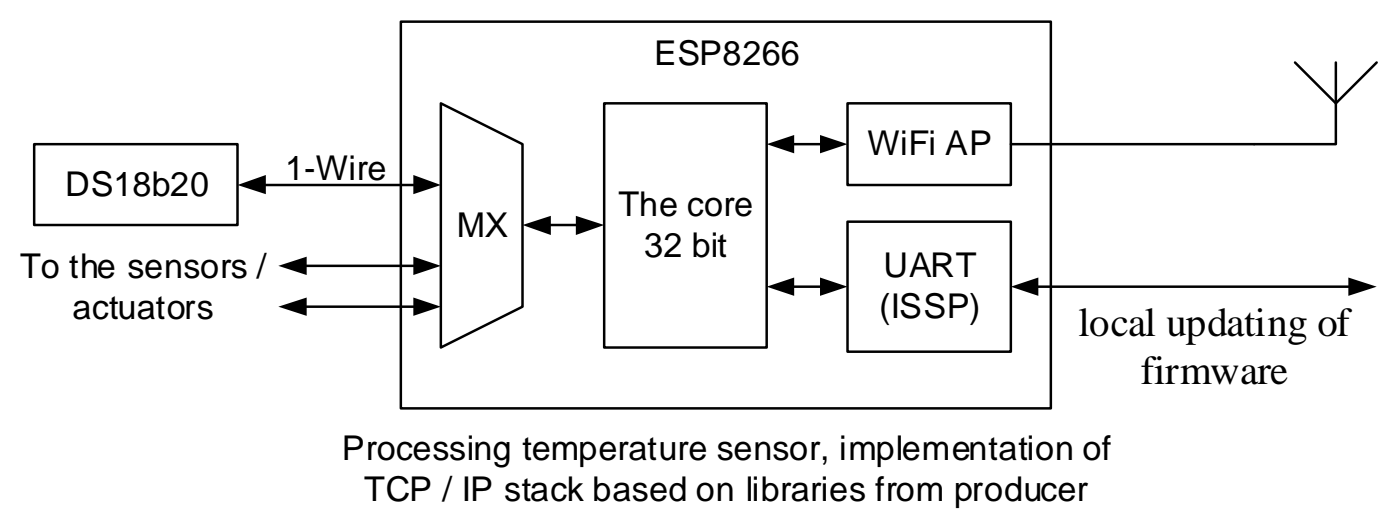

Fig. 2. COMMS based Wi-Fi module and temperature sensor

As a sensor, a DS18B20 temperature sensor was chosen which uses a 1-Wire tire to communicate with the microcontroller. This sensor has a range of measured temperature - from $-55^{\circ} \mathrm{C}$ to $+125^{\circ} \mathrm{C}$. The accuracy of temperature measurement is in the range from $-10{ }^{\circ} \mathrm{C}$ to $+85^{\circ} \mathrm{C}- \pm 0.5^{\circ} \mathrm{C}$. The programmable resolution of the thermometer is $9 \ldots 12$ digits.

The firmware of the Wi-Fi module has been replaced by an alternative (NodeMcu), an alternative version of the firmware is characterized by the presence of the LUA scripting language interpreter. This choice was due to the availability of a large number of adapted libraries, to work with various interfaces and sensors. The module was reprogrammed in the Explorer environment.

The library is used in this work: for emulating a 1-Wire tire, for managing the outputs (GPIO), for using the Wi-Fi interface, for implementing the TCP / IP stack. These libraries are available for use and do not require licensing. After turning on the Wi-Fi module goes into the access point mode, and creates a new Wi-Fi network. To ensure that subscribers who join this network do not manually configure it, a DHCP server was created to organize the distribution of IP addresses. The data from the microcontroller can be obtained via the UART interface or via a software-implemented TCP interface.

So, for the exchange of messages, a TCP server was created, and a Web server was created on top of it. When the subscriber of the Wi-Fi network performs a request to the TCP server, the request passes through the Web server, it is measured using a temperature sensor. After receiving data from the temperature sensor, a response is formed for the subscriber. A web page is generated that reflects the current temperature value, in reply.

After the communication with the subscriber of the network is completed, the TCP server is always waiting for a new communication session. This implementation of COMMS is characterized by the fact that the minimum number of components is involved, and the implementation of all work is concentrated on the internal resources of the ESP8266 module's Wi-Fi. Update took place through the UART interface. The software implementation of the work algorithm for this module is performed in the LUA language.

\section{CONCLUSIONS}

Computational complexity of algorithms for primary data processing and the intensity of information flows passing through it are the main criteria in the formation of the structure of the COMMS. The proposed basic structural solutions of COMMS provide solutions to the vast majority of applied tasks in hierarchical Ethernetoriented CPSs. It is recommended to implement a TSPS in the form of a combination of a microcontroller with a UART-Ethernet or UART-Wi-Fi interface bridge at low computational complexity of data processing algorithms and low information traffic. It is expediently to pay attention to the UART-Wi-Fi bridge based on Espressif's SoC ESP8266 when developing low-budget cordless CPS. A more universal solution is the use of the UARTEthernet / Wi-Fi module, HLK-RM04, which supports two types of network interfaces and two independent asynchronous serial ports. If it is necessary to perform complex and resource-intensive data processing algorithms, it is advisable to use single-board microcomputer with integrated network interfaces-for example, the Raspberry $\mathrm{Pi}$ product line, or their functional counterparts. If it is necessary to industrialize the COMMS, a possible solution may be the use of standard industrial computers, although this will significantly increase the cost of CPS.

\section{REFERENCES}

[1] Melnyk A. O. Kiberfizychni systemy: problemy stvorennya ta napryamy rozvytku [Cyber-physical systems: problems of development and lines of development]. Visnyk Natsional'noho universytetu “L'vivs'ka politekhnika” “Komp'yuterni systemy ta merezhi”. Lviv, Ukraine, 2014, vol. 806, pp. 154-161 (In Ukrainian).

[2] Melnyk A.O. Bahatorivneva bazova platforma kiberfizychnykh system. [Multi core platform cyber-physical systems]. "Kiberfizychni systemy: dosyahnennya ta vyklyky" " Materialy pershoho naukovoho seminaru”. Lviv, Ukraine, 2015, pp. 5-15 (In Ukrainian).

[3] Melnyk A. O. Intehratsiya rivniv kiberfizychnoyi systemy [Integration levels cyberphysical system]. Visnyk Natsional'noho 
universytetu "L'vivs'ka politekhnika" "Komp"yuterni systemy ta merezhi”. Lviv, Ukraine, 2015, vol. 830, pp. 61-67 (In Ukrainian).

[4] Grebeniak A. V., Golembo V. A. Chotyryrivneva arkhitektura avtonomnoho mobil'noho ahenta dlya detsentralizovanoho samoorhanizovanoho kolektyvu. [Four level architecture autonomous mobile agent for decentralized self-organized collective.]. Naukovyy visnyk Chernivets'koho universytetu “Komp'yuterni systemy ta komponenty". Chernivtsi, Ukraine, 2015, vol. 6.1, pp. 86-92 (In Ukrainian).

[5] Miyushkovych E. G., Paramud Y. S. Telekomunikatsiyni interfeysy kiberfizychnykh system: kontseptsiya zastosuvannya

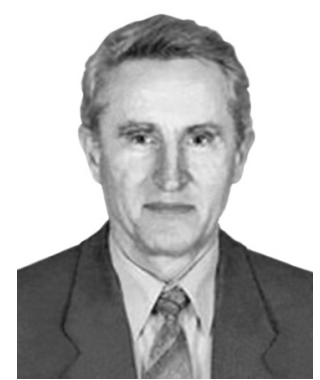

Yaroslav Paramud - Ph. D., associate professor of the Computer Engineering Department at Lviv Polytechnic National University. In 1964 he graduated from Automation Faculty of Lviv Polytechnic Institute. His $\mathrm{Ph}$. D. thesis was defended in 1987. Research interests - processing radar information, research algorithms and structures specialized computing devices and systems. Number of scientific publications - more than 30 , has 13 copyright certificates.

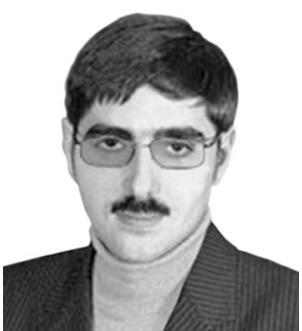

Eugene Miyushkovych senior teacher of the Computer Engineering Department at Lviv Polytechnic National University.. In 2001, he graduated from Lviv Polytechnic National University as master of computer systems and networks.
[Telecommunication interfaces of cyber-physical systems: the concept of application]. Materialy I Naukovoho seminaru, 25-26 chervnya 2015 roku "Kiberfizychni systemy dosyahnennya ta vyklyky”. Lviv, Ukraine, 2015, pp. 28-36 (In Ukrainian).

[6] Miyushkovych E. G. Osoblyvosti klasyfikatsiyi ta zastosuvannya telekomunikatsiynykh interfeysiv u kiberfizychnykh systemakh. [Classification features and application telecommunication interfaces in cyber-physical systems]. Visnyk Natsional'noho universytetu "L'vivs'ka politekhnika" "Komp'yuterni systemy ta merezhi”. Lviv, Ukraine, 2015, vol. 830, pp. 106-115 (In Ukrainian).

From 2009 to 2012, is studying at graduate school in the specialty 05.13.13 "Computing machines, systems and networks".

Author and co-author of 8 scientific papers. Took part in 11 conferences and seminars.

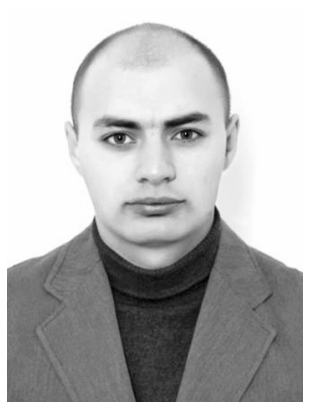

Andrii Grebeniak - assistant of the Computer Engineering Department at Lviv Polytechnic National University.

In 2008, graduated from Lviv Polytechnic National University as engineer in computer systems and networks.

From 2009 to 2012, is studying at graduate school in the specialty 05.13.05 "Computer systems and components".

Subject of research - autonomous decentralized measuring computer systems, theory of collective behavior of intelligent systems, multiagent systems. In his scientific heritage, he has 6 publications and participant of 3 international scientific conferences. 